1 Highly Active Platinum Single-Atom Catalyst Grafted onto 3D Carbon Cloth Support

\title{
for the Electrocatalytic Hydrogen Evolution Reaction
}

3

Po-Wei Yu ${ }^{1}$, Sait Elmas ${ }^{1}$, Xun Pan $^{1}$, Yanting Yin ${ }^{1}$, Christopher T. Gibson ${ }^{1,2}$, Gunther G. Andersson ${ }^{1}$ 5 and Mats R. Andersson ${ }^{1 *}$

6

${ }^{1}$ - Flinders Institute for Nanoscale Science \& Technology, Flinders University, Bedford Park SA, Adelaide,

Australia.

2 - Flinders Microscopy and Microanalysis, College of Science and Engineering, Flinders University, Bedford

Park, SA 5042, Australia

11

Sait Elmas: sait.elmas@,flinders.edu.au;

\section{ABSTRACT}

Platinum single-atom catalysts (PtSACs) on 3D support are emerging as new frontier in catalysis due to their atom-economy, outstanding performance and the advantage to bridge the gap between homogeneous and heterogeneous catalysis. Here we report on a simple, single-step electrochemical grafting attachment of a metal-selective ligand, 2,6:2',2"-terpyridine, and the synthesis of platinum

21 single-atom electrocatalyst via metal uptake from aqueous salt solution. At an ultra-low loading of

$220.26 \pm 0.02 \mu \mathrm{g} \cdot \mathrm{cm}^{-2}$ of platinum, the single atom catalysts supported on porous $3 \mathrm{D}$ carbon cloth electrode via chemical bonding revealed the highest reported mass activity of $77.1 \mathrm{~A}^{\circ} \mathrm{g}_{\mathrm{Pt}}{ }^{-1}$ at $\eta=50$ $\mathrm{mV} / \mathrm{RHE}$ compared to the commercial catalyst $20 \% \mathrm{Pt} / \mathrm{C}$. The electro-grafted terpyridine ligand can also act as an effective scavenger for leached platinum from the counter electrode during extended operational hours. The method to make the PtSAC is facile, non-hazardous and versatile without

27 involving any elaborative pre- and/or post-treatment steps and, the value of the added platinum to the 28 ligand is only $0.1 \mathrm{US} \$ \cdot \mathrm{m}^{-2}$. 
29 Keywords: Single-atom catalyst, platinum, terpyridine, electro-grafting, self-supported electrodes, hydrogen evolution, electrocatalysis.

\section{INTRODUCTION}

Hydrogen is considered the most promising and competitive energy carrier, as it is clean, renewable and available in abundance. With an energy density of $120-140 \mathrm{MJ} / \mathrm{kg}$ being three times higher than the same amount of energy gasoline can provide and the possibility to feed hydrogen gas into the existing infrastructures, the transition from fossil based fuels to the hydrogen economy has started. ${ }^{1,2}$ Undoubtedly, when combined with renewable energy sources such as wind and solar power, hydrogen has enormous potential to become one of the main alternative energy carrier to push toward zero greenhouse gas emissions in the near future. ${ }^{3-5}$ At present, steam reforming of methanol and ethanol is the main process in hydrogen production. However, the product of the steam reforming is not only hydrogen and water; leaving inevitably the carbon dioxide footprint behind, the question remains as to whether steam-reforming of hydrocarbons can still be defined as "clean". Moreover, the steam reforming process requires high temperature and separation methods making hydrogen as energy carrier also less profitable. ${ }^{6-8}$ In contrast, hydrogen production by means of electrocatalytic water splitting is a completely clean method with lower costs and profitable oxygen by-product, which has great potential to produce molecular hydrogen on large scales. ${ }^{9,10}$ In electrocatalytic water splitting, platinum based catalysts are used both as cathode and anode due to the high activity of the platinum metal at low overpotentials. ${ }^{11-13}$ With its scarcity in the earth's crust (less than $1 \mu \mathrm{g} \cdot \mathrm{kg}^{-1}$ availability) and the indispensable applications in catalysis, electronics, jewellery and anti-cancer drugs platinum has inevitably become the most expensive and strategic commodity for the industry nations. ${ }^{14}$ Hence, to meet the growing demand and to create higher commercial value, it is of great importance to make every single atom count in electrocatalysis. 

electrocatalysis due to the atom-economy, where every single atom is involved in the catalytic process. Single-atom catalysts embedded in rationally designed coordination environments and immobilized on stable supports provide the unique advantage to bridge the gap between homogenous and heterogeneous catalysis and keeping the amount of scarce metals at minimum. The synthetic tools to make such single atoms catalysts using Pt include multi-stage wet-chemical synthesis, ${ }^{15-18}$ atomic layer deposition, ${ }^{12,19,20}$ electrochemical deposition ${ }^{21-23}$ and other elaborative methods. ${ }^{24}$

A more elegant method to provide a well-defined coordination environment for stable singleatom catalysts is the electrochemical grafting method. In attaching diazonium-substituted ligands onto graphitic and metallic surfaces via strong co-valent chemical bond the grafting method has proven as a powerful tool to address interfacial chemistry. ${ }^{22,25-27}$ group metals. The coordination environment is provided by the $2,6: 2^{\prime}, 2^{\prime \prime}$-terpyridine pincer type ligand ${ }^{28-30}$ that allows tailored mass loading by uptake of $\mathrm{Pt}^{2+}$ from commercially available platinum 69 salts in aqueous solution. Furthermore, the electro-grafted terpyridine ligand on the 3-dimensional 70 carbon cloth electrode serves as highly efficient metal scavenger for recovering leached platinum 71 from the counter electrode (Fig. 1). Platinum leaching from the counter electrodes during long-term 72 operation in acidic media has been in focus of recent studies questioning the reliability of Pt as 73 counter electrode in membrane-less electrolysers. ${ }^{31-35}$ Significant loss of the noble metal stemming

74 from the counter electrode is observed in the electrolyte. ${ }^{33,36}$ In this study, leached platinum atoms are scavenged by the terpyridine ligand and utilized in-situ as additional single-atom catalysts improving the catalysts performance as the hydrogen evolution reaction progresses. 


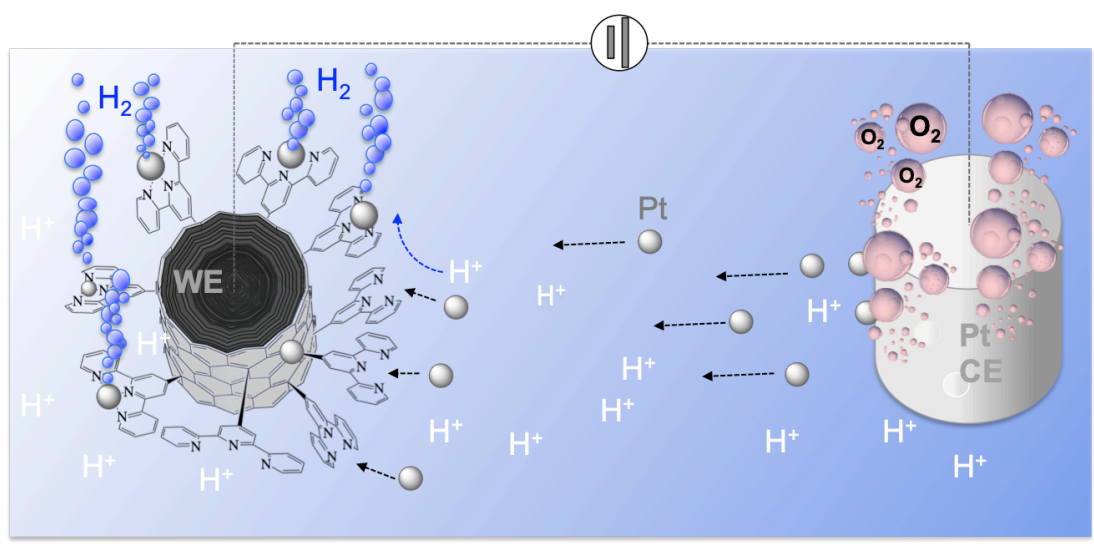

79 Figure 1: Hydrogen production on Pt single atoms embedded in terpyridine coordination environment electro-

80 grafted onto the carbon cloth (WE) fibre. The electro-grafted ligand acts also as vacancy for leached Pt ions

81 from the counter electrode (CE).

The preparation of the electrocatalyst from commercially available products is non-

84 hazardous, versatile and does not require any elaborative and expensive pre- and/or post-treatment. To

85 the best of our knowledge, this is first report on single-step electro-grafting method to chemically bind $862,6: 2^{\prime}, 2$ '-terpyridine directly onto 3D carbon support and fabrication of single-atom catalysts by 87 simple metal uptake from commercially available metal salts.

88

\section{EXPERIMENTAL}

Materials and methods. Sulfuric acid (98\%, Scharlau), hydrochloric acid (Sigma Aldrich,

92 analytical grade) and potassium hydroxide (Scharlau, Spain) were diluted with MilliQ water (TOC 1.8

93 ppm, $\left.18.2 \Omega \mathrm{Mcm} @ 25^{\circ} \mathrm{C}\right)$ to the required molarities in $100 \mathrm{~mL}$ volumetric flasks. Sodium nitride,

$94 \mathrm{NaNO}_{2}$, and potassium tetrachloroplatinate, $\mathrm{K}_{2}\left[\mathrm{PtCl}_{4}\right]$, were purchased from Sigma Aldrich and used 95 without further purification. $4^{\prime}$-Amino-2,2' $: 6^{\prime}, 2^{\prime}$-terpyridine was purchased from Shanghai UCHEM 96 Inc. (Shanghai, China) and used without further purification. 
Vulcan - Cloth (W1S1009) were purchased from FuelCellStore (Fuel Cell Etc, USA) and cut into $1 \mathrm{x}$

$5 \mathrm{~cm}^{2}$ pieces to obtain the carbon cloth (CC) and 20\% $0.03 \mathrm{mg} \mathrm{Pt} / \mathrm{C}$ electrodes.

XPS was applied using $\mathrm{Mg} \mathrm{K} \alpha$ radiation to determine the elemental composition and the chemical states of all components. Under the condition chosen, XPS has a probing depth of less than $10 \mathrm{~nm}$,

102 depending on the electron mean free path. ${ }^{37}$ The apparatus was built by SPECS (Berlin, Germany)

103 with a non-monochromatic X-ray source and has and a base pressure of a few $10^{-10}$ mbar with the

104 details described in. ${ }^{38}$ The angle between the X-ray source and the analyser is $54.7^{\circ}$. At a pass energy

105 of $10 \mathrm{eV}$ the $\mathrm{FWHM}$ of the $\mathrm{Ag} 3 \mathrm{~d}_{5 / 2}$ peak is $<1 \mathrm{eV}$. The uncertainty of the peak positions is typically

$1060.2 \mathrm{eV}$. High-resolution scans were recorded at a step size of $0.1 \mathrm{eV}$ for $\mathrm{C}, \mathrm{O}, \mathrm{N}$ and $\mathrm{Pt}$ at a pass energy of $10 \mathrm{eV}$. The acquired spectra were calibrated by setting the $\mathrm{C} 1 \mathrm{~s}$ peak of $\mathrm{C}-\mathrm{C} \mathrm{sp}^{3}$ carbon to $285.0 \mathrm{eV}$.

Data analysis was performed with CasaXPS software (Casa Software Ltd.) and selected graphs were plotted with the Qti Plot software.

112 laser wavelength of $532 \mathrm{~nm}$ with a $40 \mathrm{X}$ objective (numerical aperture 0.60 ). Typical integration times

113 for single Raman spectra were 5 to $15 \mathrm{~s}$ and averaged from 2 to 3 repetitions. 10 to 15 spectra were 114 acquired per sample with spectra analysed using Witec project 4.1.

115 Thermogravimetric analysis (TGA) measurements were performed on PerkinElmer TGA 1168000 , with the temperature range of $30-1000{ }^{\circ} \mathrm{C}$ under nitrogen gas protection, and the heating ramp 117 of $10^{\circ} \mathrm{C} \cdot \mathrm{min}^{-1}$. All samples were dried in a vacuum oven at RT prior to the measurements.

$1190.5 \mathrm{M} \mathrm{HCl}$ for the electro-grafting step and $0.5 \mathrm{M} \mathrm{H}_{2} \mathrm{SO}_{4}$ for electrocatalytic studies using modified carbon cloth as working electrode (WE), a platinum wire or graphite rod as counter electrode (CE)

121 and $\mathrm{Ag} \mid \mathrm{AgCl}(1 \mathrm{M} \mathrm{KCl})$ as reference electrode. Recorded potentials were converted into reversible 122 hydrogen electrode (RHE) as reported elsewhere. ${ }^{39}$ 


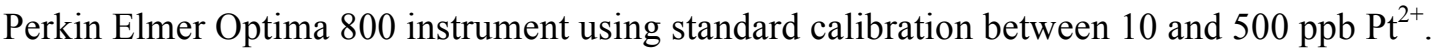

1291.0 volts using the plain carbon cloth $(1 \times 5 \mathrm{~cm})$ as working, $\mathrm{Pt}$ wire as counter and $\mathrm{Ag} \mid \mathrm{AgCl}(1 \mathrm{M}$

$130 \mathrm{KCl}$ ) as reference electrode. After the grafting step was finished, the submerged (grafted) surface area

131 of CC was measured and the obtained Terpy@CC electrode was stored in a $0.1 \mathrm{M} \mathrm{KOH}$ solution for

132 at least 30 minutes, then washed with MilliQ water, then $\mathrm{EtOH}$ and dried in the vacuum oven overnight.

$\boldsymbol{P t}^{2+}$ uptake by the terpy@CC electrode. The terpy@CC electrodes were cut to small pieces

135 (typically $2 \mathrm{~cm} \times 1 \mathrm{~cm}$ ) and submerged in dark inside a closed vial containing $20 \mathrm{~mL}$ aqueous

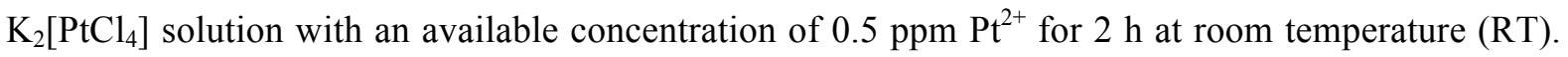

137 The MilliQ water was purged for at least 30 min with $\mathrm{N}_{2}$ prior to dissolving the platinum salt. After 2

$138 \mathrm{~h}$ uptake, the closed vial was gently shaken and $18 \mathrm{~mL}$ of the $\mathrm{Pt}^{2+}$ solution was analysed by ICP OES.

139 To validate the $\mathrm{Pt}^{2+}$ uptake by terpy@CC, two control experiments were conducted with pure CC

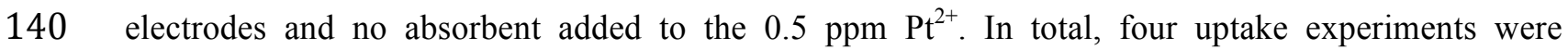
141 conducted, and the remaining $\mathrm{Pt}^{2+}$ solutions after uptake were analysed by ICP OES. Whereas no 142 concentration difference between both control samples was detected by ICP OES, the concentration 143 difference after uptake by the terpy@CC electrode was calculated to be $0.26 \pm 0.02 \mu \mathrm{g} \cdot \mathrm{cm}^{-2}$.

\section{RESULTS AND DISCUSSION}

\section{Synthesis and performance of the Pt single-atom catalysts in HER}

148 binding character to noble metals and has a widespread applications in molecular architectures. ${ }^{40-45}$ 
149 The plain carbon cloth (CC) has high electrical conductivity and is an ideal support material for self150 supported electrocatalysts. ${ }^{46,47}$ The flexible 3-dimonsional woven structure that provides relatively

151 large specific surface area can accommodate a high number of grafted ligands via covalent bonds, 152 enabling the combination of single-atom chemistry with 3D supported catalysis. To make the stable 3153 dimenisional and metal-chelating electrode, the terpyridine ligand was electro-grafted onto the carbon 154 cloth electrode under cathodic reduction in $0.5 \mathrm{M} \mathrm{HCl}$ solution using cyclic voltammetry. 4155 Diazonium-2,2':6,2"-terpyridine was generated in-situ with sodium nitrite in $0.5 \mathrm{M} \mathrm{HCl}$ and subjected 156 to electrochemical grafting (see Experimental and Scheme 1a). ${ }^{27,48,49}$ As shown in Fig 2a, a strong 157 reduction event appears at $-0.68 \mathrm{~V}$ vs. RHE during cathodic cycling in $0.5 \mathrm{M} \mathrm{HCl}$ electrolyte solution.

158 The strong reduction event originates from the homolytic cleavage of $\mathrm{C}^{-} \mathrm{N}_{2}{ }^{+}$bond creating a 159 terpyridine radical that immediately reacts with the carbon surface (Scheme 1b). Within the 160 subsequent numbers of cathodic sweeps, the intensity of observed reduction peak decreases rapidly, a 161 typical indication for surface saturation with electro-grafted ligands. ${ }^{50,51}$ The rapid decrease in the 162 reduction peak and the absence of additional reduction events during progressing cyclic voltammetry 163 sweeps is indicative for single layer grafted terpyridine ligands. Note that, from one single ligand 164 solution a series of terpyridine-grafted CC electrodes could be prepared highlighting the advantage of 165 the electrochemical grafting method. Thermogravimetric analysis shows the ligand being stable on the 166 carbon cloth surface up to $300^{\circ} \mathrm{C}$ (terpy@CC, Fig. 2b) and XPS surface analysis of the electro-grafted 167 carbon cloth electrode detected high content (up to 10\%) of nitrogen on the surface, which is 168 attributed to the ligand (vide infra). 
(a)

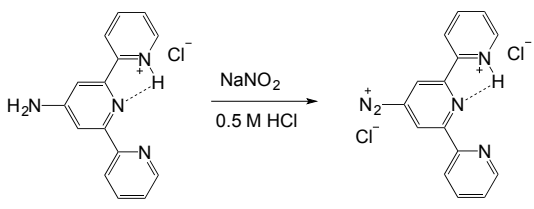

(b)
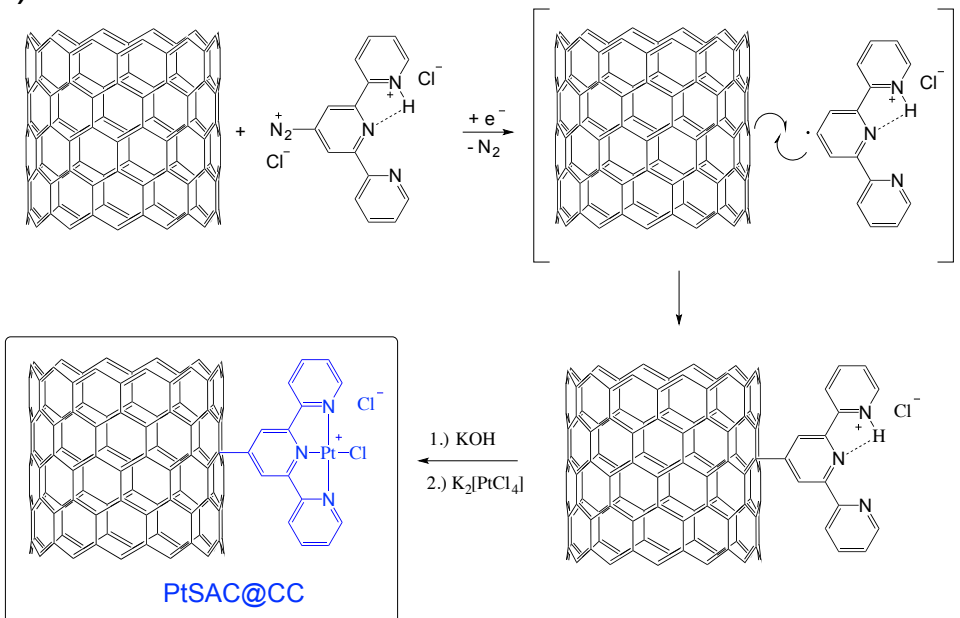

170 Scheme 1: (a) In-situ preparation of 4-diazonium 2,2':6,2"-terpyridine in $0.5 \mathrm{M} \mathrm{HCl}$ electrolyte solution using

171 sodium nitrite as oxidant and, (b) subsequent electrochemical grafting of the terpyridine ligand onto the 3-

172 dimenisonal carbon cloth at $-0.68 \mathrm{~V}$ vs. RHE. The synthesis of the platinum single-atom electrocatalyst, PtSAC,

173 is achieved by metal uptake from aqueous $\mathrm{K}_{2}\left[\mathrm{PtCl}_{4}\right]$ solution.

174

175

To make the single-atom Pt electrocatalyst (PtSAC@CC-0.5), the terpy-grafted CC electrode,

176 terpy@CC, was submerged in aqueous potassium tetrachloroplatinate solution $\left(0.5 \mathrm{ppm} \mathrm{Pt}^{2+}\right)$ for $2 \mathrm{~h}$

177 at RT. In our studies, we found that increased temperature, exposure to light and presence of

178 dissolved oxygen caused formation of Pt deposition on the non-grafted CC electrode itself. Hence, to avoid deposition of nano-particulate platinum on the $\mathrm{CC}$ surface, the $\mathrm{Pt}^{+2}$ uptake was conducted under

$180 \mathrm{~N}_{2}$ protection and in the dark. Under these conditions, repeated uptake experiments from $0.5 \mathrm{ppm} \mathrm{Pt}^{2+}$

181 ions revealed mass loadings of $0.26 \pm 0.02 \mu \mathrm{g} \cdot \mathrm{cm}^{-2}$ of platinum on the terpy@CC electrodes,

182 whereas no Pt uptake from pure CC could be detected by ICP OES. 

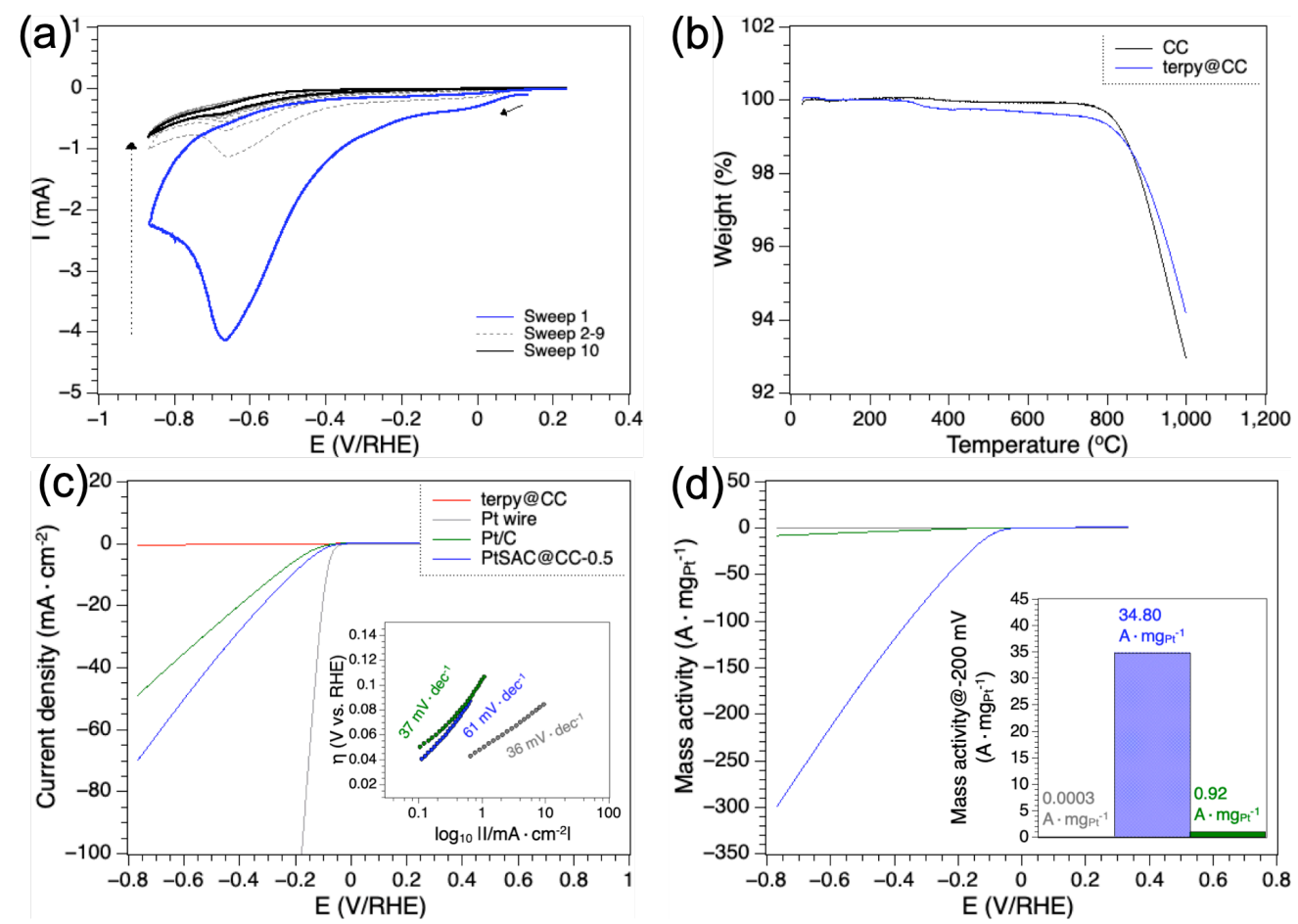

184 Figure 2: Recorded cyclic voltammogram of electro-grafting 4-amino terpyridine onto the carbon electrode in

$1850.5 \mathrm{M} \mathrm{HCl}$ electrolyte solution. (b) TGA thermogram of the electro-grafted ligand (terpy@CC) compared to the

186 blank support carbon cloth (CC). (c) Linear sweep voltammogram of the Pt single-atom catalyst (PtSAC@CC-

1870.5 ) compared to the free ligand terpy@CC (red), commercial catalyst 0.03 mg 20\% Pt/C@CC (green) and the

188 Pt wire (grey); inset shows the calculated Tafel slopes with their respective colour scheme. (d) Calculated mass activity of the catalysts as function of applied potential vs. RHE in their respective colour; inset shows comparative mass activity at the overpotential of $200 \mathrm{mV}$.

$193 \mathrm{H}_{2} \mathrm{SO}_{4}$ solution using a $\mathrm{Pt}$ wire and $\mathrm{Ag} \mid \mathrm{AgCl}(1 \mathrm{M} \mathrm{KCl})$ as counter and reference electrode, 194 respectively. For comparisons, commercially available benchmark catalyst on carbon cloth, $20 \% 0.03$ mg Pt/C, a platinum wire and the free ligand electro-grafted onto the $\mathrm{CC}$ electrode were tested under

196 the same conditions. For a better accuracy of the performance data and to avoid potential metal

197 leaching from the Pt counter electrode and re-deposition onto the working electrode in acidic media, 198 only 10 cyclic voltammetry sweeps at $10 \mathrm{mV} \cdot \mathrm{s}^{-1}$ were applied. Figure $2 \mathrm{c}$ shows the last forward 
199 sweep of the recorded cyclic voltammograms, each. It appears that the single atom catalyst slightly 200 outperforms the commercially available benchmark catalyst, $20 \% 0.03 \mathrm{mg} \mathrm{Pt} / \mathrm{C}$, when normalised to 201 the geometric surface area. To generate $10 \mathrm{~mA} \cdot \mathrm{cm}^{-2}$, PtSAC@CC-0.5 requires $210 \mathrm{mV}$ vs. RHE, 202 which is $59 \mathrm{mV}$ lower than $\mathrm{Pt} / \mathrm{C}$. The Tafel slopes were calculated in the low overpotential range of $20340-110 \mathrm{mV}$ to be 61,37 and $36 \mathrm{mV} \cdot \mathrm{dec}^{-1}$ for the PtSAC@CC-0.5, Pt/C and the Pt wire, respectively.

205 Table 1: Calculated mass activity ratios of the PtSAC and 20\% Pt/C studied in this work and compared to the 206 activity ratios of Pt single-atom catalysts reported in literature.

\begin{tabular}{ccc} 
Overpotential & \multicolumn{2}{c}{ Mass activity ratio between studied catalyst and $20 \% \mathrm{Pt} / \mathrm{C}$} \\
$\underline{\eta(\mathrm{V} / \mathrm{RHE})}$ & $\underline{T^{2}}$ & \multicolumn{1}{c}{$\underline{\text { Literature }}$} \\
$50 \mathrm{mV}$ & 77.1 & $74.4^{52}, 40^{53}, 37.4^{12}, 4.3^{13}$ \\
$100 \mathrm{mV}$ & 51.3 & $47.56^{53}, 26.9^{54}, 6.1^{13}$ \\
$200 \mathrm{mV}$ & 37.8 & $6.3^{55}$ \\
\hline
\end{tabular}

207 overpotentials of 50,100 and $200 \mathrm{mV}$, respectively. 

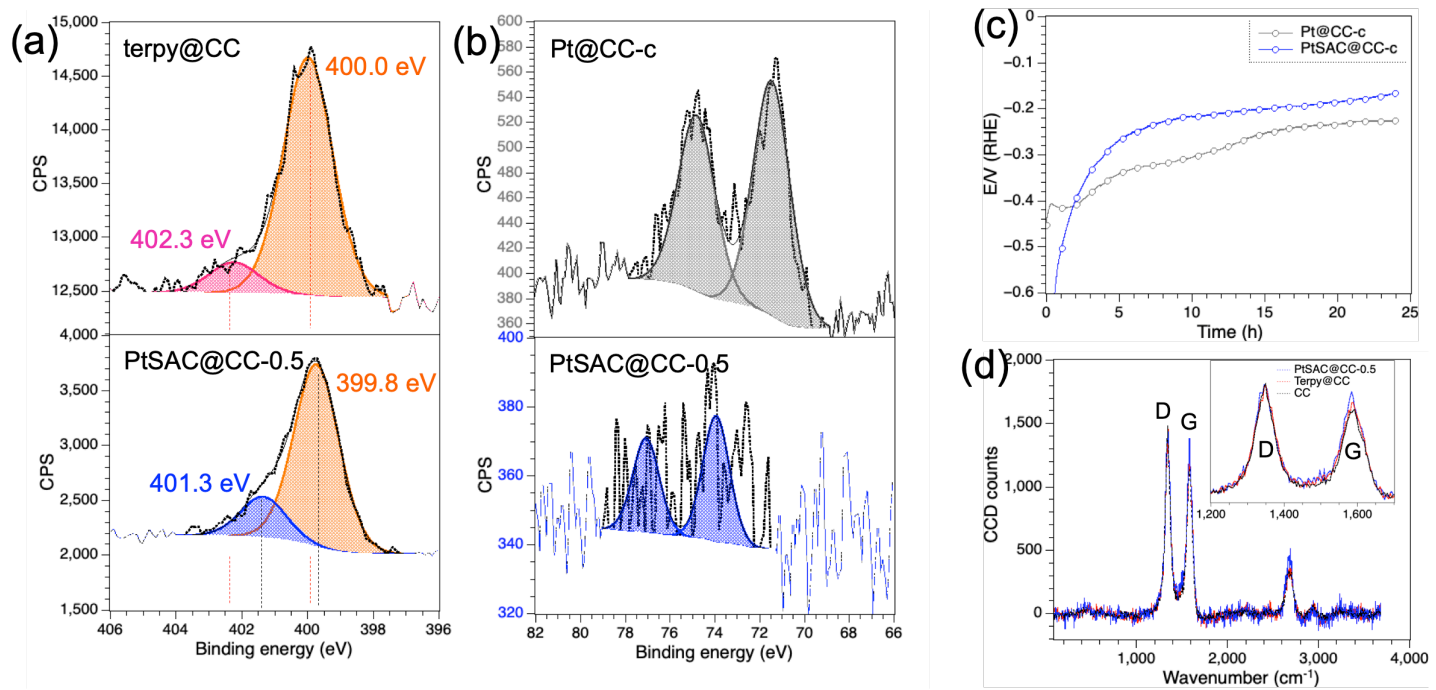

218 Figure 3: (a) Fitted N1s and (b) Pt4f core level spectra of the electro-grafted terpyridine onto carbon cloth

219 (terpy@CC), ultra-low platinum-loaded single atom catalyst (PtSAC@CC-0.5) and Pt-loaded carbon cloth after

22024 h chronoamperometric (Pt@CC-c); the ultra-low loading of the electro-grafted terpy@CC electrode was

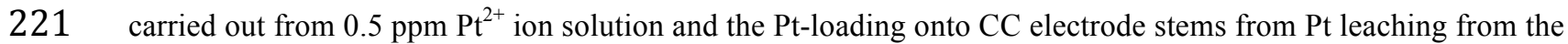

$222 \mathrm{CE}$ and re-deposition onto the WE; (c) Chronoamperometric HER at $10 \mathrm{~mA} \mathrm{~cm}^{-2}$ for $24 \mathrm{~h}$ on PtSAC@CC-0.5 and CC electrode. Due to the Pt leaching and re-deposition onto the working electrodes, both electrodes became PtSAC@CC-c and Pt@CC-c; (d) Overlapped D and G Raman bands of CC, Pt@CC, terpy@CC and PtSAC@CC-0.5.

227 the valence state of the metal in PtSAC@CC-0.5 and to understand the participation of the 228 coordination environment in the electro-grafted terpyridine ligand. The fitted $\mathrm{N}(1 \mathrm{~s})$ and $\mathrm{Pt}(4 \mathrm{f})$ core 229 level spectra are shown in Fig. 3 and summarized in Table 2. Electro-grafted CC showed under XPS 230 more than $10 \%$ nitrogen with the $\mathrm{N} 1 \mathrm{~s}$ core level spectrum fitted to a main peak at $400 \mathrm{eV}$ 231 accompanied by a peak at $402.3 \mathrm{eV}$ (Fig. 3a). The first peak is assigned to the pyridine structure while 232 the second peak originates from ammonium-N after electro-grafting the ligand under acidic conditions 233 (see mechanism in Scheme 1). ${ }^{56}$ After Pt uptake from $0.5 \mathrm{ppm} \mathrm{Pt}^{2+}$ ions, both $\mathrm{N}$ peaks were shifted 234 toward lower binding energies (BE) where the $=\mathrm{N}-\mathrm{H}^{+}$peak featuring a significant shift to lower 
235 binding energies $(\triangle \mathrm{BE}-1.0 \mathrm{eV})$. The XPS core level spectra of platinum exhibit two asymmetric 236 components in the $\mathrm{Pt} 4 \mathrm{f}$ region $\left(\mathrm{Pt}_{4} \mathrm{f}_{5 / 2}\right.$ and $\left.\mathrm{Pt} 4 \mathrm{f}_{7 / 2}\right)$ and are separated by $3.33 \mathrm{eV}$ as expected for Pt.

237 Leached platinum that only originates from the counter electrode during 24 hours

238 chronoamperometric water splitting and re-deposited onto the WE (Pt@CC-c, Fig. 3b, top panel)

239 exhibits only zero-valent platinum $\left(\mathrm{Pt}^{0}\right)$, whereas the terpyridine-grafted electrode pre-loaded with

$240 \mathrm{Pt}^{2+}$ ions from $0.5 \mathrm{ppm}$ solution shows trace amounts $\mathrm{Pt}^{2+}$ at $73.8 \mathrm{eV}$ as oxide under XPS (see Fig. $3 \mathrm{~b}$

241 bottom panel and Table 2). ${ }^{53,57}$ The binding energy of the first component is $71.5 \mathrm{eV}$ assigned to

242 metallic $\mathrm{Pt}^{58}$ The binding energy of the second component is at $73.9 \mathrm{eV}$ and assigned to $\mathrm{Pt}^{2+}$ as part of

$243 \mathrm{PtCl}_{2}$ or $\mathrm{PtO}$ bound into the terpyridine units. Although 10 linear sweeps were applied to

244 PtSAC@CC-0.5, XPS analysis of the electrode showed no indication of reduced platinum.

246 Table 2: Fitted XPS core level data in Pt4f, their atomic composition and ratios as well as the Raman D/G ratios 247 of studied electrodes.

\begin{tabular}{|c|c|c|c|c|c|c|c|c|}
\hline Electrode & $\% \mathrm{C}$ & $\% \mathrm{O}$ & $\% \mathrm{~N}$ & $\% \mathrm{Pt}$ & $\mathrm{N} / \mathrm{Pt}$ & $\mathrm{Pt}^{0}$ & $\mathrm{Pt}^{2+}$ & $\mathrm{D} / \mathrm{G}$ \\
\hline $\mathrm{CC}$ & 95.06 & 4.94 & 0 & 0 & - & - & - & 1.28 \\
\hline $\mathrm{Pt} @ \mathrm{CC}-\mathrm{c}$ & 96.15 & 3.67 & & 0.19 & - & 71.5 & & 1.14 \\
\hline Terpy@CC & 78.41 & 11.17 & 10.71 & - & - & - & - & 1.17 \\
\hline PtSAC@CC-0.5 & 76.05 & 11.62 & 12.27 & 0.03 & 409 & & 73.9 & 1.07 \\
\hline PtSAC@CC-0.5c & 72.83 & 14.38 & 11.09 & 1.46 & 7.6 & 71.4 & 73.9 & \\
\hline PtSAC@CC-165 & 66.85 & 18.85 & 9.50 & 2.81 & 3.38 & 72.0 & 73.7 & \\
\hline
\end{tabular}

248

After chronoamperometric water splitting at PtSAC-0.5 (Fig. 3c), XPS detected a mixture of zero- and bi-valent platinum on the electrode, where $\mathrm{Pt}^{0}$ is major valence state $(\mathrm{PtSAC} @ \mathrm{CC}-0.5 \mathrm{c}$ in

251 Fig. 4b). In stark contrast to the ligand-free $\mathrm{CC}$ electrode, much stronger deposition onto the terpygrafted WE was detected by XPS. The Pt content increased from $0.03 \%$ to $1.46 \%$ after 24 h operation,

253 whereas the increase of Pt content on ligand-free CC was only by $0.19 \%$. This observation is also 254 indicated by the steep decrease of the overpotential at the PtSAC- $0.5 \mathrm{c}$ electrode during the 

electrode is immediately bound into chelating interface of the working electrode.
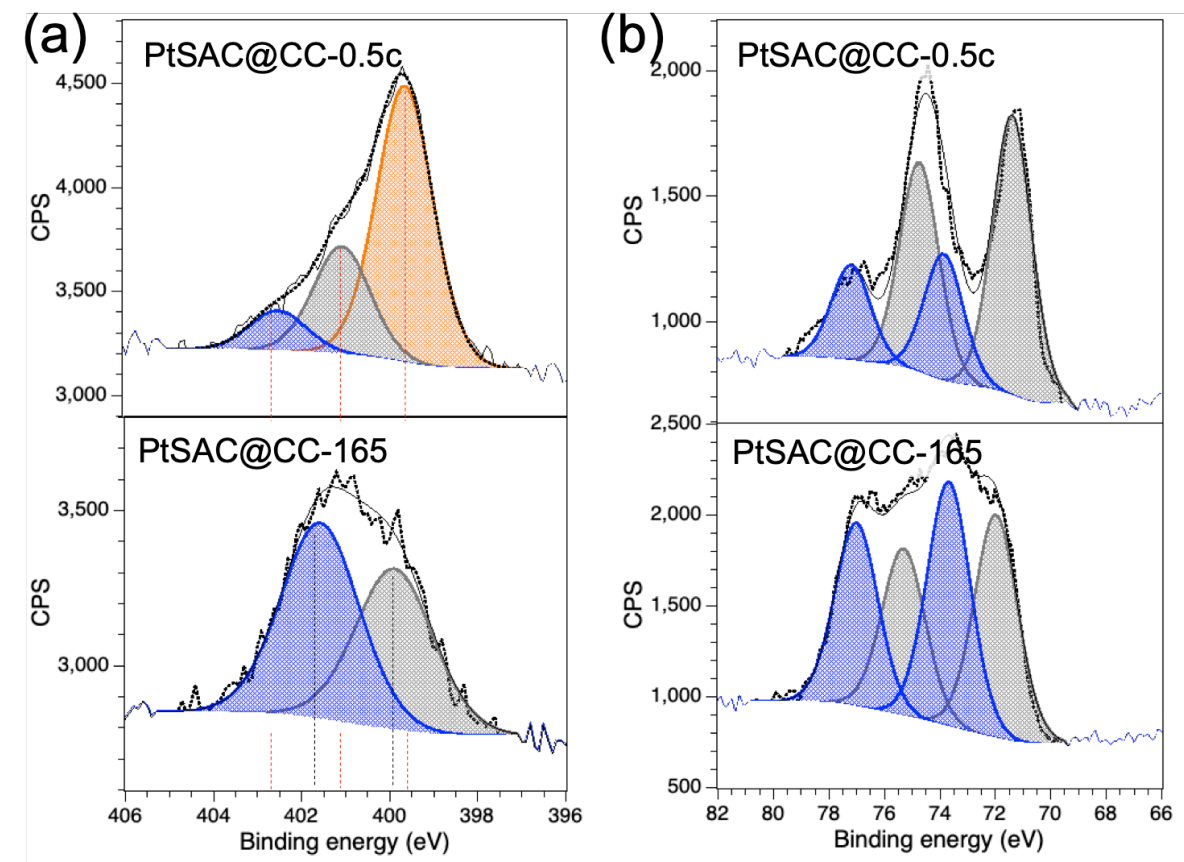

259 Figure 4: Fitted (a) N1s and (b) Pt4f core level spectra of the ultra-low platinum-loaded single atom catalyst

260 (PtSAC@CC-0.5c) after 24 h chronoamperometry (top panels) and after uptake of $\mathrm{Pt}^{2+}$ from $165 \mathrm{ppm} \mathrm{Pt}$ ion

261 solution (bottom panels).

When using graphite rod as counter electrode in a separate chronoamperometric HER

264 experiment on PtSAC-0.5, XPS detected $\mathrm{Pt}^{2+}$ as only valence state with no loss of metal after $3 \mathrm{~h}$ of 265 operation suggesting that presence of the $\mathrm{Pt}^{0}$ in the previous experiment (PtSAC-0.5c) was largely 266 contributed by leached metal from the Pt CE (Fig. S1, Supporting Information). Using again Pt as CE 267 in further control experiments with 8 hours chronoamperometric HER on the PtSAC@CC-0.5 and CC 268 electrodes showed 240-260 ppb Pt being leached into the electrolyte solution, when the electrolytes 269 were analysed by ICP OES. It was also found that re-deposited Pt onto CC in both valence states $\mathrm{Pt}^{0}$ 270 and $\mathrm{Pt}^{2+}$ was removed by more than $71 \%$ when the working electrode was sonicated for 40 minutes in 
271 pure $\mathrm{H}_{2} \mathrm{O}$ and then subjected to surface analysis by XPS (see Fig. 5b). In contrast, bound $\mathrm{Pt}^{2+}$ into the terpy@CC electrode was not removed from the chelating pockets after the same time of sonication

273 (Fig. 5a). Again, this method clearly highlights the main advantage of the terpyridine ligand on CC 274 support as it acts as efficient scavenger for leached platinum.
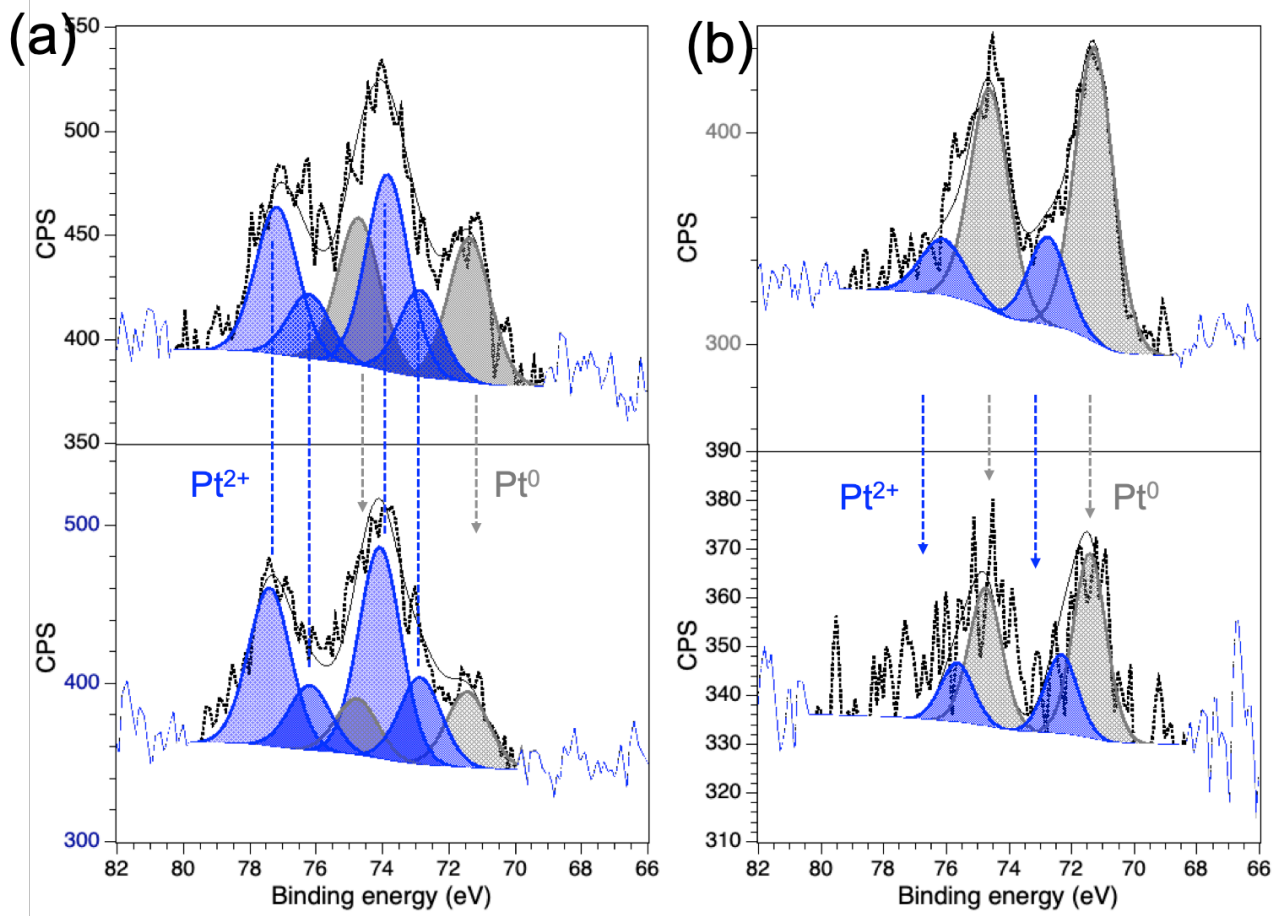

277 Figure 5: (a) Fitted Pt4f core level spectra of the ultra-low platinum-loaded single atom catalyst (PtSAC@CC-

$0.5)$ after $8 \mathrm{~h}$ chronoamperometry (top panels) and after 40 min sonication (bottom panel) using the Pt wire as

CE; (b) Fitted Pt4f core level spectra of leached Pt and deposited onto CC after $8 \mathrm{~h}$ chronoamperometry (top panels) and after 40 min sonication (bottom panel) using the Pt wire as CE. of PtSAC@CC-0.5c, that is assigned to the nitrogen in the free ligand (orange) and the N-donors

284 bound to $\mathrm{Pt}^{0}$ (grey) and $\mathrm{Pt}^{2+}$ (blue), respectively. Although significant amounts of $\mathrm{Pt}$ were leached and 285 bound to the terpy@ CC interface, only less than a half of the available ligands were occupied by Pt 286 (N/Pt ratio of 7.6 in Table 2). A nearly full saturation with Pt was found in uptake experiments within 

in PtSAC@CC-165, Table 2). Notably, the fitted components in Pt4f core level data revealed high amounts of zero-valent platinum in PtSAC@CC-165, although the uptake was from $\mathrm{Pt}^{2+}$ ions. In line with the reported studies in the literature, it appears to be difficult to obtain either one of the valence $\mathrm{Pt}^{0}, \mathrm{Pt}^{2+}$ or $\mathrm{Pt}^{4+}$ at higher metal loadings. ${ }^{59}$ Of particular note is also the observed $\mathrm{I}_{\mathrm{D}} / \mathrm{I}_{\mathrm{G}}$ ratio in the Raman spectra (Fig. 3d). The intensity and positions of Raman peaks can provide important structural information for the carbon samples. The G peak between 1560 to $1600 \mathrm{~cm}^{-1}$ is associated with a vibrational mode of $\mathrm{sp}^{2}$-hybridized graphene planes. The D peak at 1300 to

$2951400 \mathrm{~cm}^{-1}$ is the band associated with defects. The ratio of $\mathrm{D}$ band to $\mathrm{G}$ band peak intensities, $I_{D} / I_{G}$, has been used to probe the level of disorder of carbon materials. ${ }^{52}$ Non-grafted CC displays the highest ratio between the D- and G-band indicative for highest defects of the carbon surface in this series. As the surface is manipulated further, more symmetry is induced as indicated in the decay of the $\mathrm{I}_{\mathrm{D}} / \mathrm{I}_{\mathrm{G}}$ ratio that approaches a ratio of $1 / 1$. This tendency has also been observed in similar catalysts systems and explained by coverage of the defects after manipulating the carbon fibre surface (Table $2)^{52}$

\section{CONCLUSIONS}

Functionalisation of the 3D carbon cloth surface with well-defined coordination environment by simple electrochemical grafting methods enables to access ultra-low loaded and high performing single atom catalysts for electrocatalytic applications. In this study, using the terpyridine ligand as strong chelator for noble metals, platinum single-atom catalysts were made in two simple steps without involving elaborative synthetic methods. The obtained PtSAC@CC-0.5 revealed the lowest reported mass loading of $0.26 \pm 0.02 \mu \mathrm{g} \bullet \mathrm{cm}^{-2}$ and the highest reported mass activity ratio of 77.1

$311 \mathrm{~A} \cdot \mathrm{g}_{\mathrm{Pt}}{ }^{-1}$ at $\eta=50 \mathrm{mV} / \mathrm{RHE}$ in the electrocatalytic hydrogen production compared to the benchmark catalyst Pt/C. This method provides dual benefit for the scarcity of the noble metals. In pushing the Pt 
313 value down to $0.1 \mathrm{US} \$ \cdot \mathrm{m}^{-2}$ compared to $2.30 \mathrm{US} \$ \cdot \mathrm{m}^{-2}$ for $20 \% 0.03 \mathrm{mg} \mathrm{Pt} / \mathrm{C}$ (see Supporting 314 Information) it makes literally every single atom count in electrocatalysis and recovers leached metal 315 from counter electrodes at the same time.

316

\section{ACKNOWLEDGEMENT}

318 S. E. and M. R. A. thank the Australian Government through the Australian Research Council's 319 Discovery Projects funding scheme (project DP210101243). The authors acknowledge the expertise, 320 equipment and support provided by Microscopy Australia and the Australian National Fabrication 321 Facility (ANFF) at the South Australian nodes under the National Collaborative Research 322 Infrastructure Strategy. The authors acknowledge the expertise, equipment and support provided by 323 Flinders Microscopy and Microanalysis (FMMA) at Flinders University. This project was also supported by the French-Australian Research Network on Energy and Conversion through the International Research Network (project IRN FACES).

\section{AUTHORS CONTRIBUTION}

P.-W. Y. and S. E. contributed equally.

\section{CONFLICT OF INTEREST}

The authors declare no conflict of interest.

\section{ABBREVIATIONS}

334 CC - Carbon cloth electrode.

terpy - Terpyridine ligand

336 terpy@CC - terpyridine ligand electro-grafted onto the CC surface

337 PtSAC - Platinum single-atom catalyst.

338 PtSAC@CC - Platinum single-atom catalyst bound into terpy@CC. 
PtSAC@CC-0.5 - PtSAC@CC obtained from 0.5 ppm Pt ${ }^{2+}$ solution.

340 PtSAC@CC-0.5c - PtSAC@CC obtained from 0.5 ppm $\mathrm{Pt}^{2+}$ solution and after chronoamperometric

HER.

342 PtSAC@CC-165 - PtSAC@CC obtained from 165 ppm Pt ${ }^{2+}$ solution.

343 Pt@CC-c - leached platinum from Pt CE and re-deposited onto the CC working electrode after 344 chronoamperometric HER.

\section{REFERENCES}

347

(1) Abe, J. O.; Popoola, A. P. I.; Ajenifuja, E.; Popoola, O. M. Hydrogen Energy, Economy and Storage: Review and Recommendation. International Journal of Hydrogen Energy 2019, 44 (29), 15072-15086. https://doi.org/10.1016/j.ijhydene.2019.04.068.

(2) Pudukudy, M.; Yaakob, Z.; Mohammad, M.; Narayanan, B.; Sopian, K. Renewable Hydrogen Economy in Asia - Opportunities and Challenges: An Overview. Renewable and Sustainable Energy Reviews 2014, 30, 743-757. https://doi.org/10.1016/j.rser.2013.11.015.

(3) Hsu, S.-H.; Miao, J.; Zhang, L.; Gao, J.; Wang, H.; Tao, H.; Hung, S.-F.; Vasileff, A.; Qiao, S. Z.; Liu, B. An Earth-Abundant Catalyst-Based Seawater Photoelectrolysis System with 17.9\% Solar-to-Hydrogen Efficiency. Adv. Mater. 2018, 30 (18), 1707261. https://doi.org/10.1002/adma.201707261.

(4) Lin, L.; Zhou, W.; Gao, R.; Yao, S.; Zhang, X.; Xu, W.; Zheng, S.; Jiang, Z.; Yu, Q.; Li, Y.W.; Shi, C.; Wen, X.-D.; Ma, D. Low-Temperature Hydrogen Production from Water and Methanol Using Pt/ $\alpha$-MoC Catalysts. Nature 2017, 544 (7648), 80-83. https://doi.org/10.1038/nature21672.

(5) Momirlan, M.; Veziroglu, T. N. Current Status of Hydrogen Energy. Renewable and Sustainable Energy Reviews 2002, 6 (1-2), 141-179. https://doi.org/10.1016/S1364-0321(02)00004-7.

(6) LeValley, T. L.; Richard, A. R.; Fan, M. The Progress in Water Gas Shift and Steam Reforming Hydrogen Production Technologies - A Review. International Journal of Hydrogen Energy 2014, 39 (30), 16983-17000. https://doi.org/10.1016/j.ijhydene.2014.08.041.

(7) Palo, D. R.; Dagle, R. A.; Holladay, J. D. Methanol Steam Reforming for Hydrogen Production. Chem. Rev. 2007, 107 (10), 3992-4021. https://doi.org/10.1021/cr050198b. 
(8) Holladay, J. D.; Hu, J.; King, D. L.; Wang, Y. An Overview of Hydrogen Production Technologies. Catalysis Today 2009, 139 (4), 244-260. https://doi.org/10.1016/j.cattod.2008.08.039.

(9) Nong, H. N.; Gan, L.; Willinger, E.; Teschner, D.; Strasser, P. IrOx Core-Shell Nanocatalysts for Cost- and Energy-Efficient Electrochemical Water Splitting. Chem. Sci. 2014, 5 (8), 2955-2963. https://doi.org/10.1039/C4SC01065E.

(10) You, B.; Sun, Y. Innovative Strategies for Electrocatalytic Water Splitting. Acc. Chem. Res. 2018, 51 (7), 1571-1580. https://doi.org/10.1021/acs.accounts.8b00002.

(11) Reier, T.; Oezaslan, M.; Strasser, P. Electrocatalytic Oxygen Evolution Reaction (OER) on Ru, Ir, and Pt Catalysts: A Comparative Study of Nanoparticles and Bulk Materials. ACS Catal. 2012, 2 (8), 1765-1772. https://doi.org/10.1021/cs3003098.

(12) Cheng, N.; Stambula, S.; Wang, D.; Banis, M. N.; Liu, J.; Riese, A.; Xiao, B.; Li, R.; Sham, T.-K.; Liu, L.-M.; Botton, G. A.; Sun, X. Platinum Single-Atom and Cluster Catalysis of the Hydrogen Evolution Reaction. Nat Commun 2016, 7 (1), 13638. https://doi.org/10.1038/ncomms13638.

(13) Cheng, X.; Li, Y.; Zheng, L.; Yan, Y.; Zhang, Y.; Chen, G.; Sun, S.; Zhang, J. Highly Active, Stable Oxidized Platinum Clusters as Electrocatalysts for the Hydrogen Evolution Reaction. Energy Environ. Sci. 2017, 10 (11), 2450-2458. https://doi.org/10.1039/C7EE02537H.

(14) Reith, F.; Campbell, S. G.; Ball, A. S.; Pring, A.; Southam, G. Platinum in Earth Surface Environments. Earth-Science Reviews 2014, 131, 1-21. https://doi.org/10.1016/j.earscirev.2014.01.003.

(15) Liang, S.; Hao, C.; Shi, Y. The Power of Single-Atom Catalysis. ChemCatChem 2015, 7 (17), 2559-2567. https://doi.org/10.1002/cctc.201500363.

(16) Elmas, S.; Beelders, W.; Bradley, S. J.; Kroon, R.; Laufersky, G.; Andersson, M.; Nann, T. Platinum Terpyridine Metallopolymer Electrode as Cost-Effective Replacement for Bulk Platinum Catalysts in Oxygen Reduction Reaction and Hydrogen Evolution Reaction. ACS Sustainable Chemistry \& Engineering 2017, 5 (11), 10206-10214. https://doi.org/10.1021/acssuschemeng.7b02198.

(17) Pu, Z.; Amiinu, I. S.; Cheng, R.; Wang, P.; Zhang, C.; Mu, S.; Zhao, W.; Su, F.; Zhang, G.; Liao, S.; Sun, S. Single-Atom Catalysts for Electrochemical Hydrogen Evolution Reaction: Recent Advances and Future Perspectives. Nano-Micro Lett. 2020, 12 (1), 21. https://doi.org/10.1007/s40820-019-0349-y.

(18) Cheng, N.; Zhang, L.; Doyle-Davis, K.; Sun, X. Single-Atom Catalysts: From Design to Application. Electrochem. Energ. Rev. 2019, 2 (4), 539-573.

https://doi.org/10.1007/s41918-019-00050-6. 
(19) Piernavieja-Hermida, M.; Lu, Z.; White, A.; Low, K.-B.; Wu, T.; Elam, J. W.; Wu, Z.; Lei, Y. Towards ALD Thin Film Stabilized Single-Atom Pd ${ }_{1}$ Catalysts. Nanoscale 2016, 8 (33), 15348-15356. https://doi.org/10.1039/C6NR04403D.

(20) Sun, S.; Zhang, G.; Gauquelin, N.; Chen, N.; Zhou, J.; Yang, S.; Chen, W.; Meng, X.; Geng, D.; Banis, M. N.; Li, R.; Ye, S.; Knights, S.; Botton, G. A.; Sham, T.-K.; Sun, X. Single-Atom Catalysis Using Pt/Graphene Achieved through Atomic Layer Deposition. Sci Rep 2013, 3 (1), 1775. https://doi.org/10.1038/srep01775.

(21) Zhang, L.; Han, L.; Liu, H.; Liu, X.; Luo, J. Potential-Cycling Synthesis of Single Platinum Atoms for Efficient Hydrogen Evolution in Neutral Media. Angew. Chem. Int. Ed. 2017, 56 (44), 13694-13698. https://doi.org/10.1002/anie.201706921.

(22) Tavakkoli, M.; Holmberg, N.; Kronberg, R.; Jiang, H.; Sainio, J.; Kauppinen, E. I.; Kallio, T.; Laasonen, K. Electrochemical Activation of Single-Walled Carbon Nanotubes with Pseudo-Atomic-Scale Platinum for the Hydrogen Evolution Reaction. ACS Catal. 2017, 7 (5), 3121-3130.

(23) Zhang, J.; Zhao, Y.; Guo, X.; Chen, C.; Dong, C.-L.; Liu, R.-S.; Han, C.-P.; Li, Y.; Gogotsi, Y.; Wang, G. Single Platinum Atoms Immobilized on an MXene as an Efficient Catalyst for the Hydrogen Evolution Reaction. Nat Catal 2018, 1 (12), 985-992. https://doi.org/10.1038/s41929-018-0195-1.

(24) Chen, Y.; Ji, S.; Chen, C.; Peng, Q.; Wang, D.; Li, Y. Single-Atom Catalysts: Synthetic Strategies and Electrochemical Applications. Joule 2018, 2 (7), 1242-1264. https://doi.org/10.1016/j.joule.2018.06.019.

(25) Gautier, C.; López, I.; Breton, T. A Post-Functionalization Toolbox for Diazonium (Electro)-Grafted Surfaces: Review of the Coupling Methods. Mater. Adv. 2021, 2 (9), 2773-2810. https://doi.org/10.1039/D1MA00077B.

(26) Bangle, R.; Sampaio, R. N.; Troian-Gautier, L.; Meyer, G. J. Surface Grafting of Ru(II) Diazonium-Based Sensitizers on Metal Oxides Enhances Alkaline Stability for Solar Energy Conversion. ACS Appl. Mater. Interfaces 2018, 10 (3), 3121-3132. https://doi.org/10.1021/acsami.7b16641.

(27) Ghasemi, E.; Alimardani, E.; Shams, E.; Koohmareh, G. A. Modification of Glassy Carbon Electrode with Iron-Terpyridine Complex and Iron-Terpyridine Complex Covalently Bonded to Ordered Mesoporous Carbon Substrate: Preparation, Electrochemistry and Application to $\mathrm{H} 2 \mathrm{O} 2$ Determination. Journal of Electroanalytical Chemistry 2017, 789, 92-99. https://doi.org/10.1016/j.jelechem.2017.01.043.

(28) Albrecht, M.; van Koten, G. Platinum Group Organometallics Based on "Pincer" Complexes: Sensors, Switches, and Catalysts. Angewandte Chemie International 
Edition 2001, 40 (20), 3750-3781. https://doi.org/10.1002/15213773(20011015)40:20<3750::AID-ANIE3750>3.0.C0;2-6.

(29) Klein, A.; Elmas, S.; Butsch, K. Oxido Pincer Ligands - Exploring the Coordination Chemistry of Bis(Hydroxymethyl)Pyridine Ligands for the Late Transition Metals. European Journal of Inorganic Chemistry 2009, 2009 (15), 2271-2281. https://doi.org/10.1002/ejic.200900023.

(30) Klein, A.; Butsch, K.; Elmas, S.; Biewer, C.; Heift, D.; Nitsche, S.; Schlipf, I.; Bertagnolli, H. Oxido-Pincer Complexes of Copper(II) - An EXAFS and EPR Study of Mono- and Binuclear [(PydotH2)CuCl2]n (N=1 or 2). Polyhedron 2012, 31 (1), 649-656. https://doi.org/10.1016/j.poly.2011.10.023.

(31) Chen, R.; Yang, C.; Cai, W.; Wang, H.-Y.; Miao, J.; Zhang, L.; Chen, S.; Liu, B. Use of Platinum as the Counter Electrode to Study the Activity of Nonprecious Metal Catalysts for the Hydrogen Evolution Reaction. ACS Energy Lett. 2017, 2 (5), 1070-1075. https://doi.org/10.1021/acsenergylett.7b00219.

(32) Lee, J.; Bang, J. H. Reliable Counter Electrodes for the Hydrogen Evolution Reaction in Acidic Media. ACS Energy Lett. 2020, 5 (8), 2706-2710. https://doi.org/10.1021/acsenergylett.0c01537.

(33) Gu, C.; Norris, B. C.; Fan, F.-R. F.; Bielawski, C. W.; Bard, A. J. Is Base-Inhibited Vapor Phase Polymerized PEDOT an Electrocatalyst for the Hydrogen Evolution Reaction? Exploring Substrate Effects, Including Pt Contaminated Au. ACS Catalysis 2012, 2 (5), 746-750. https://doi.org/10.1021/cs3000107.

(34) Tian, M.; Cousins, C.; Beauchemin, D.; Furuya, Y.; Ohma, A.; Jerkiewicz, G. Influence of the Working and Counter Electrode Surface Area Ratios on the Dissolution of Platinum under Electrochemical Conditions. ACS Catal. 2016, 6 (8), 5108-5116. https://doi.org/10.1021/acscatal.6b00200.

(35) Esposito, D. V. Membraneless Electrolyzers for Low-Cost Hydrogen Production in a Renewable Energy Future. Joule 2017, 1 (4), 651-658. https://doi.org/10.1016/j.joule.2017.07.003.

(36) Winther-Jensen, B.; Fraser, K.; Ong, C.; Forsyth, M.; MacFarlane, D. R. Conducting Polymer Composite Materials for Hydrogen Generation. Advanced Materials 2010, 22 (15), 1727-1730. https://doi.org/10.1002/adma.200902934.

(37) Gall, D. Electron Mean Free Path in Elemental Metals. Journal of Applied Physics 2016, 119 (8), 085101. https://doi.org/10.1063/1.4942216.

(38) Acres, R. G.; Ellis, A. V.; Alvino, J.; Lenahan, C. E.; Khodakov, D. A.; Metha, G. F.; Andersson, G. G. Molecular Structure of 3-Aminopropyltriethoxysilane Layers Formed on Silanol-Terminated Silicon Surfaces. J. Phys. Chem. C 2012, 116 (10), 6289-6297. https://doi.org/10.1021/jp212056s. 
485

486

487

488

489

490

491

492

493

494

495

496

497

498

499

500

501

502

503

504

505

506

507

508

509

510

511

512

513

514

515

516

517

518

519

520

521

522

(39) Elmas, S.; Macdonald, T.; Skinner, W.; Andersson, M.; Nann, T. Copper Metallopolymer Catalyst for the Electrocatalytic Hydrogen Evolution Reaction (HER). Polymers 2019, 11 (1), 110. https://doi.org/10.3390/polym11010110.

(40) Cummings, S. D. Platinum Complexes of Terpyridine: Synthesis, Structure and Reactivity. Coordination Chemistry Reviews 2009, 253 (3-4), 449-478. https://doi.org/10.1016/j.ccr.2008.04.013.

(41) Swiegers, G. F.; Malefetse, T. J. New Self-Assembled Structural Motifs in Coordination Chemistry. Chem. Rev. 2000, 100 (9), 3483-3538. https://doi.org/10.1021/cr990110s.

(42) Hofmeier, H.; Schubert, U. S. Recent Developments in the Supramolecular Chemistry of Terpyridine-Metal Complexes. Chem. Soc. Rev. 2004, 33 (6), 373399. https://doi.org/10.1039/B400653B.

(43) Whittell, G. R.; Hager, M. D.; Schubert, U. S.; Manners, I. Functional Soft Materials from Metallopolymers and Metallosupramolecular Polymers. Nature Materials 2011, 10 (3), 176-188. https://doi.org/10.1038/nmat2966.

(44) Dewi, M. R.; Gschneidtner, T. A.; Elmas, S.; Ranford, M.; Moth-Poulsen, K.; Nann, T. Monofunctionalization and Dimerization of Nanoparticles Using Coordination Chemistry. ACS Nano 2015, 9 (2), 1434-1439. https://doi.org/10.1021/nn5058408.

(45) Gao, Z.; Han, Y.; Gao, Z.; Wang, F. Multicomponent Assembled Systems Based on Platinum(II) Terpyridine Complexes. Acc. Chem. Res. 2018, 51 (11), 2719-2729. https://doi.org/10.1021/acs.accounts.8b00340.

(46) Tian, J.; Liu, Q.; Asiri, A. M.; Sun, X. Self-Supported Nanoporous Cobalt Phosphide Nanowire Arrays: An Efficient 3D Hydrogen-Evolving Cathode over the Wide Range of PH 0-14. J. Am. Chem. Soc. 2014, 136 (21), 7587-7590. https://doi.org/10.1021/ja503372r.

(47) Sun, H.; Yan, Z.; Liu, F.; Xu, W.; Cheng, F.; Chen, J. Self-Supported Transition-MetalBased Electrocatalysts for Hydrogen and Oxygen Evolution. Adv. Mater. 2020, 32 (3), 1806326. https://doi.org/10.1002/adma.201806326.

(48) Tregubov, A. A.; Vuong, K. Q.; Luais, E.; Gooding, J. J.; Messerle, B. A. Rh(I) Complexes Bearing $N, N$ and $N, P$ Ligands Anchored on Glassy Carbon Electrodes: Toward Recyclable Hydroamination Catalysts. J. Am. Chem. Soc. 2013, 135 (44), 16429-16437. https://doi.org/10.1021/ja405783g.

(49) Binding, S. C.; Pernik, I.; Gonçales, V. R.; Wong, C. M.; Webster, R. F.; Cheong, S.; Tilley, R. D.; Garcia-Bennett, A. E.; Gooding, J. J.; Messerle, B. A. Simultaneous Functionalization of Carbon Surfaces with Rhodium and Iridium Organometallic Complexes: Hybrid Bimetallic Catalysts for Hydroamination. Organometallics 2019, 38 (4), 780-787. https://doi.org/10.1021/acs.organomet.8b00726. 
523

524

525

526

527

528

529

530

531

532

533

534

535

536

537

538

539

540

541

542

543

544

545

546

547

548

549

550

551

552

553

554

555

556

557

558

559

560

(50) Pinson, J.; Podvorica, F. Attachment of Organic Layers to Conductive or Semiconductive Surfaces by Reduction of Diazonium Salts. Chem. Soc. Rev. 2005, 34 (5), 429. https://doi.org/10.1039/b406228k.

(51) Elmas, S.; Skipper, K.; Salehifar, N.; Jamieson, T.; Andersson, G. G.; Nydén, M.; Leterme, S. C.; Andersson, M. R. Cyclic Copper Uptake and Release from Natural Seawater-A Fully Sustainable Antifouling Technique to Prevent Marine Growth. Environ. Sci. Technol. 2021, 55 (1), 757-766. https://doi.org/10.1021/acs.est.0c06231.

(52) Ji, J.; Zhang, Y.; Tang, L.; Liu, C.; Gao, X.; Sun, M.; Zheng, J.; Ling, M.; Liang, C.; Lin, Z. Platinum Single-Atom and Cluster Anchored on Functionalized MWCNTs with Ultrahigh Mass Efficiency for Electrocatalytic Hydrogen Evolution. Nano Energy 2019, 63, 103849. https://doi.org/10.1016/j.nanoen.2019.06.045.

(53) Xu, J.; Zhang, C.; Liu, H.; Sun, J.; Xie, R.; Qiu, Y.; Lü, F.; Liu, Y.; Zhuo, L.; Liu, X.; Luo, J. Amorphous MoOX-Stabilized Single Platinum Atoms with Ultrahigh Mass Activity for Acidic Hydrogen Evolution. Nano Energy 2020, 70, 104529. https://doi.org/10.1016/j.nanoen.2020.104529.

(54) Yin, X.-P.; Wang, H.-J.; Tang, S.-F.; Lu, X.-L.; Shu, M.; Si, R.; Lu, T.-B. Engineering the Coordination Environment of Single-Atom Platinum Anchored on Graphdiyne for Optimizing Electrocatalytic Hydrogen Evolution. Angew. Chem. Int. Ed. 2018, 57 (30), 9382-9386. https://doi.org/10.1002/anie.201804817.

(55) Ghanim, A. H.; Koonce, J. G.; Hasa, B.; Rassoolkhani, A. M.; Cheng, W.; Peate, D. W.; Lee, J.; Mubeen, S. Low-Loading of Pt Nanoparticles on 3D Carbon Foam Support for Highly Active and Stable Hydrogen Production. Front. Chem. 2018, 6, 523. https://doi.org/10.3389/fchem.2018.00523.

(56) Murto, P.; Elmas, S.; Méndez-Romero, U. A.; Yin, Y.; Genene, Z.; Mone, M.; Andersson, G. G.; Andersson, M. R.; Wang, E. Highly Stable Indacenodithieno[3,2- $b$ ]Thiophene-Based Donor-Acceptor Copolymers for Hybrid Electrochromic and Energy Storage Applications. Macromolecules 2020, 53 (24), 11106-11119. https://doi.org/10.1021/acs.macromol.0c02212.

(57) Kunwar, D.; Zhou, S.; DeLaRiva, A.; Peterson, E. J.; Xiong, H.; Pereira-Hernández, X. I.; Purdy, S. C.; ter Veen, R.; Brongersma, H. H.; Miller, J. T.; Hashiguchi, H.; Kovarik, L.; Lin, S.; Guo, H.; Wang, Y.; Datye, A. K. Stabilizing High Metal Loadings of Thermally Stable Platinum Single Atoms on an Industrial Catalyst Support. ACS Catal. 2019, 9 (5), 3978-3990. https://doi.org/10.1021/acscatal.8b04885.

(58) Wagner, C. D. Chemical Shifts of Auger Lines, and the Auger Parameter. Faraday Discuss. Chem. Soc. 1975, 60, 291. https://doi.org/10.1039/dc9756000291.

(59) Zagoraiou, E.; Daletou, M. K.; Sygellou, L.; Ballomenou, S.; Neophytides, S. G. Highly Dispersed Platinum Supported Catalysts - Effect of Properties on the 
$561 \quad$ Electrocatalytic Activity. Applied Catalysis B: Environmental 2019, 259, 118050.

562 https://doi.org/10.1016/j.apcatb.2019.118050.

563

564

565

566 TOC FIGURE

567

568

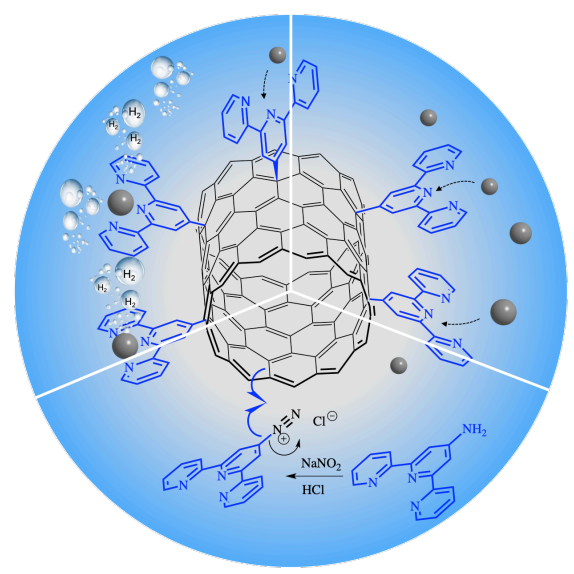

569

570

571 
573

574

575

576

577

578

579

580

581

582

583

584

585

586

587

588

589

590

591

592

593

594

595

596

597

"Highly Active Platinum Single-Atom Catalyst grafted onto 3D Carbon Cloth Support for the Electrocatalytic Hydrogen Evolution Reaction"

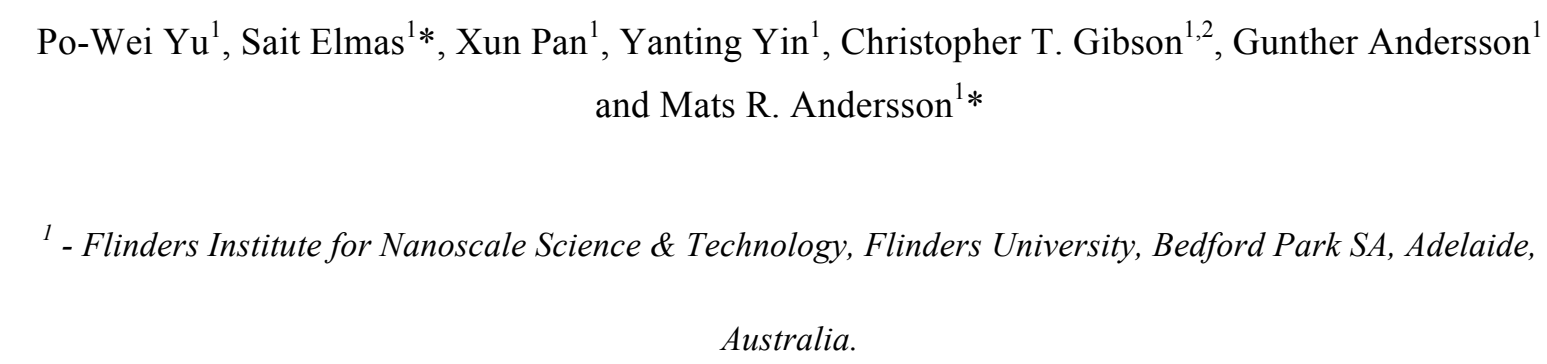

2 - Flinders Microscopy and Microanalysis, College of Science and Engineering, Flinders University, Bedford Park, SA 5042, Australia

AUTHOR'S ORCID: Sait Elmas: 0000-0002-1235-1436

Mats R. Andersson: 0000-0002-7928-8216

Gunther G. Andersson: 0000-0001-5742-3037

Xun Pan: 0000-0001-6087-7363

Christopher T. Gibson: 0000-0003-3334-5059

Calculating the value of Pt used in platinum single-atom catalysts on 3D carbon cloth electrode:

- Pt share price per ounce on 05.07.2021: 1107.1 US\$/ounce, which is $35.59 \mathrm{US} \$ / \mathrm{g}$.

- Catalyst loading in PtSAC@CC-0.5: $0.26 \mu \mathrm{g} \cdot \mathrm{cm}^{-2}=2.6 \cdot 10^{-7} \mathrm{~g} \cdot \mathrm{cm}^{-2}$

- Pt loading in PtSAC@CC-0.5 on one square meter carbon cloth: $2.6 \cdot 10^{-3} \mathrm{~g} \cdot \mathrm{m}^{-2}$

- Pt price on one square meter carbon cloth: $2.6 \cdot 10^{-3} \mathrm{~g} \cdot \mathrm{m}^{-2} * 35.59 \mathrm{US} \$ / \mathrm{g}=\mathbf{0 . 1 0} \mathbf{U S \$} \cdot \mathbf{m}^{-2}$

- For $20 \% 0.03 \mathrm{mg} \cdot \mathrm{cm}^{-2} \mathrm{Pt} / \mathrm{C}$ the Pt loading is: $6 \cdot 10^{-6} \mathrm{~g} \cdot \mathrm{cm}^{-2}$, which amounts to $\mathbf{2 . 1 3}$

598 

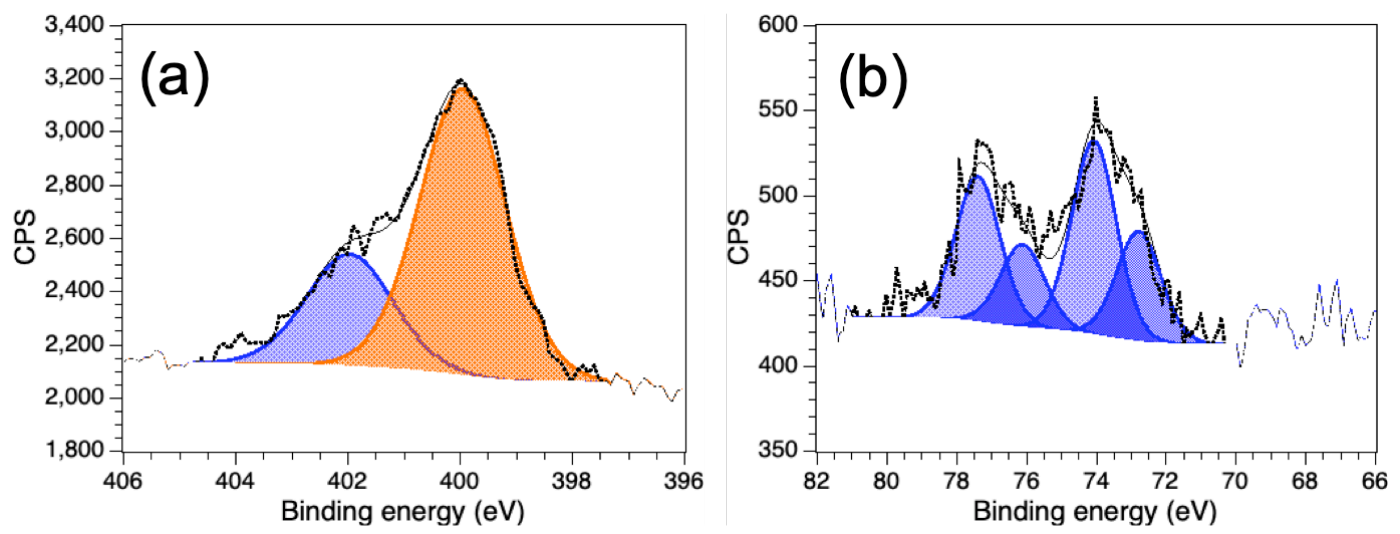

600 Figure S 1: Fitted (a) N1s and (b) Pt4f core level spectra of PtSAC-0.5 after 3 h chronoamperometric hydrogen 601 evolution reaction at $10 \mathrm{~mA} \cdot \mathrm{cm}^{-2}$ in $0.5 \mathrm{M} \mathrm{H}_{2} \mathrm{SO}_{4}$ using a graphite rod as counter electrode.

602
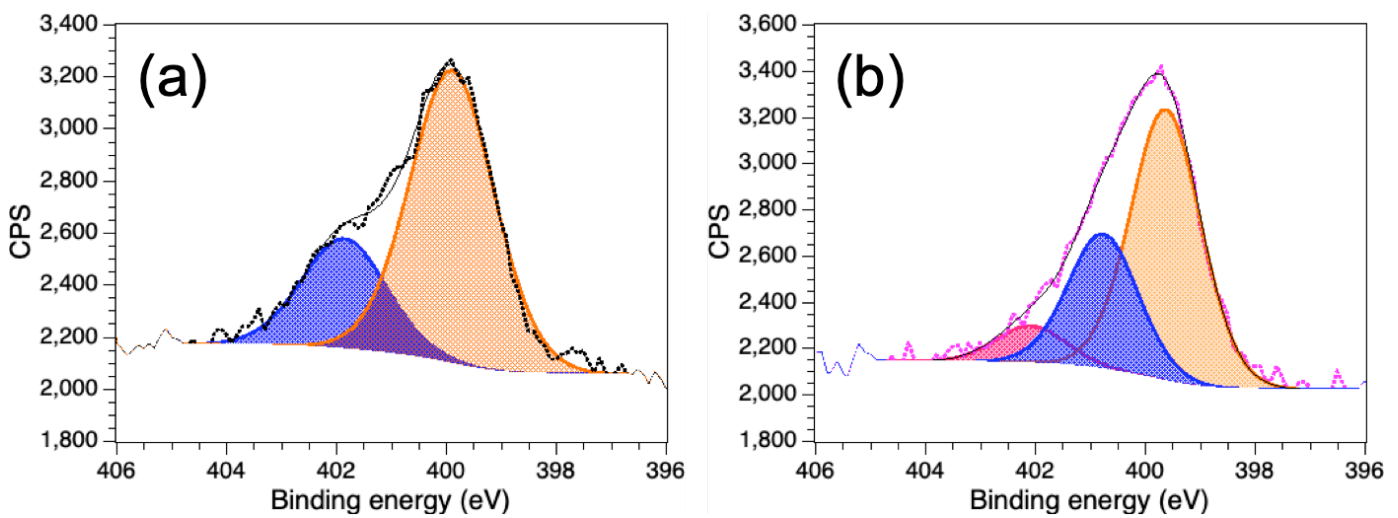

604 Figure S 2: Fitted N1s core level spectra of PtSAC-0.5 after 8 h chronoamperometric hydrogen evolution reaction at 605 $10 \mathrm{~mA}^{\bullet} \mathrm{cm}^{-2}$ in $0.5 \mathrm{M} \mathrm{H}_{2} \mathrm{SO}_{4}$ using a Pt wire as counter electrode before (a) and after (b) sonication for 4 minutes.

606

607

608 